\title{
УДК 336.64
}

\section{Прогнозная обеспеченность долга как инструмент инвестиционного мониторинга компаний*}

\author{
Д-р экон. наук Львова Н.A.n.lvova@spbu.ru \\ Канд. экон. наук Абрамишвили Н.P. n.abramishvili@spbu.ru \\ Санкт-Петербургский государственный университет \\ 199034, Россия, Санкт-Петербург, Университетская наб., д. 7/9
}

\begin{abstract}
Статья посвящена развитию методических подходов к инвестиционному мониторингу с применением инструментария оценки обеспеченности долга компаний. Цель исследования заключалась в разработке авторской модели прогнозной обеспеченности долга и обосновании ее аналитической значимости в инвестиционном мониторинге компаний. Предложенная модель апеллирует к принципам оценки корпоративных обязательств, которые применяются в теоретических моделях финансовой несостоятельности фирмы. Такой подход к формированию модели имеет определенные преимущества, не вступая в противоречие со спецификой компании, отрасли и рынка. В то жее время модель ориентирована на российские компании, что отражается в особенностях оценки свободного денежного потока. В частности, введен показатель скорректированного свободного потока на инвестированный капитал, который учитывает устойчиво высокую долю прочих доходов в общей сумме доходов российских компаний. Авторская модель апробирована на примере транспортной компании, оперирующей в одном из крупных портов Балтийского моря. Показано, что результат прогнозной обеспеченности долга в значительной степени зависит от способа формирования свободного денежного потока. Апробация модели позволилаболее детально раскрыть ее особенности, выявив преимущества и ограничения оценки. Основные рекомендации по интерпретации возможных значений прогнозной обеспеченности долга систематизированы и представлены в табличной форме. По мнению авторов, модель прогнозной обеспеченности долга будет востребована инвесторами и менеджерами в инвестиционном мониторинге компаний, внося определенный вклад в развитие таких направлений финансовой науки и практики, как управление структурой капитала, финансовая реструктуризация, оценка финансовых рисков, корпоративная финансовая диагностика и мониторинг финансовой стабильности.

Ключевые слова: инвестиции, инвестиционный мониторинг, прогнозная обеспеченность долга, свободный денежный поток, оценка инвестиционной стоимости, прогнозирование финансовой несостоятельности, формирующиеся финансовые рынки.
\end{abstract}

DOI: $10.17586 / 2310-1172-2018-11-3-44-52$

*Исследование выполнено при финансовой поддержке РФФИ в рамках научного проекта № 18-010-00085

\section{Forecasted debt coverage as a tool for investment monitoring of companies}

\author{
D.Sc. Lvova N.A.n.lvova@spbu.ru \\ Ph.D. Abramishvili N.R.n.abramishvili@spbu.ru \\ Saint Petersburg State University \\ 199034, Russia, Saint Petersburg, Universitetskaya nab., д. 7/9
}

The article is devoted to the development of methodical approaches to investment monitoring using tools for assessing the debt security of companies. The purpose of the study was to develop an author's model of the forecasted debt security and justification of its analytical significance in investment monitoring of companies. The proposed model appeals to the principles of evaluation of corporate obligations, which are used in the theoretical models of financial insolvency of the firm. This approach to the building of the model has certain advantages, without conflict with the specifics of the company, industry and the market. At the same time, the model is oriented to Russian companies, which is reflected in the characteristics of the assessment of free cash flow. In particular, the indicator of adjusted free flow on invested capital is introduced, which takes into account a consistently high share of other revenues in the total amount of income of Russian companies. The author's model is tested on the example of a transport company operating in one of the major ports of the Baltic Sea. It is shown that the result of the forecasted debt security largely 
depends on the way of calculation of free cash flow. Approbation of the model allowed to reveal its features in more detail, revealing the advantages and limitations of the evaluation. The main recommendations for interpreting the possible values of the forecasted debt securitycoefficient are systematized and presented in tabular form. According to the authors, the model of predicted debt security will be usefulfor investors and managers in investment monitoring of companies, making a contribution to the development of such areas of financial science and practice as capital structure management, financial restructuring, financial risk assessment, corporate financial diagnostics and financial stability monitoring.

Keywords: investment, investment monitoring, forecasted debt coverage, free cash flow, investment value estimation, financial distress prediction, emerging financial market.

\section{Введение}

Теория и методология оценки обеспеченности долга компаний востребована многими субъектами хозяйствования при решении многих управленческих задач. В финансовой науке данная проблематика связана с такими основополагающими вопросами, как управление структурой капитала и финансовая реструктуризация, которые входят в область ключевых компетенций финансовых менеджеров; оценка финансовых рисков, осуществляемая контрагентами и потенциальными инвесторами компании;корпоративная финансовая диагностика, представляющая интерес для внутренних и внешних финансовых аналитиков на разных этапах жизненного цикла организации;мониторинг финансовой стабильности корпоративного сектора экономики, реализуемый институциональными единицами сектора государственного управления и институтами финансовой информации.

Приведенный перечень разноплановых, но во многом взаимосвязанных вопросов нельзя назвать исчерпывающим. Важно подчеркнуть, что оценка обеспеченности долга компаний касается не только «микро-», но и «макроаналитических» задач. Безусловно, специфику макрофинансового анализа компаний, апеллирующего к обобщенным оценкам финансового состояния секторов экономики, не следует недооценивать. Характерные особенности проявляются и в отношении финансового анализа хозяйствующих субъектов, применяемого на микроэкономическом уровне. Значимые различия наблюдаются в зависимости от целей анализа, стоимости выполняемых работ, располагаемого информационного обеспечения. Тем не менее, сравнительный анализ инструментария оценки обеспеченности долга компаний даже в самом первом приближении показывает, что доступные возможности интеграции методических подходов в этой области во многом не реализованы, и, следовательно, теория и методология оценки обеспеченности долга компаний требует развития.

Оценка обеспеченности долга компаний корреспондирует с актуальными задачами управления финансовой стабильностью, выступающейне только одним из важнейших условий эффективного функционирования национальных финансовых систем, но и детерминантной экономического развития, которая может обеспечиваться институтами и политикой[15, с. 14]. Главное внимание в рамках этого аналитического направления традиционно и вполне закономерно уделяется финансовым компаниям, аккумулирующим наиболее значительный объем источников финансовой хрупкости [14]. Что касается компаний нефинансового сектора, методология оценки обеспеченности долга далеко не столь развита, а практика зачастую демонстрирует значительные упущения. Показательно, что одной из рекомендаций экспертов МВФ и Всемирного банка в рамках комплексной оценки финансового сектора России, состоявшейся в 2015 - 2016 гг., стало «расширение доступной информации о рисках нефинансовых компаний» [12, с. 31].

Новые исследования в этом направлении, в том числе публикуемые под эгидой Банка России, вносят существенный вклад в развитие макрофинансового анализа[4; 5; 13 и др.]. Вместе с тем остается немало инструментов корпоративной финансовой диагностики, адаптация которых для целей макрофинансового анализа, на наш взгляд, имеет весомую прикладную значимость [см.: 9; 19 и др.]. В частности, как было аргументировано в исследовании [18], более широко в макрофинансовых исследованиях могут использоваться агрегированные показатели обеспеченности долга, основанные на денежных потоках. Вместе с тем в российских условиях возможности применения таких показателей в силу характера доступных сведений во многом ограничены ${ }^{1}$.

В контексте микрофинансового анализа, сфера практического применения оценкиобеспеченности долга компанийсамым подробным образом, пожалуй, представлена в исследованиях структуры капитала

\footnotetext{
${ }^{1} \mathrm{~K}$ такому выводу авторы пришли на примере оценки финансового состояния российских грузоперевозчиков. В качестве примера выбраны компании, специализирующиеся на коммерческих грузоперевозках. Изначально в выборку вошло 28 публичных компаний, сведения о которых по интересующему запросу доступны в BloombergProfessional. По peзультатам углубленного анализа сведений о компаниях, выборку пришлось сократить до 17 единиц, поскольку, во-первых, экономическая деятельность отдельных компаний не соответствовала исследуемой отрасли; во-вторых, даже за трехлетний период (с 2012 по 2016 г.) по некоторым компаниям данные финансовой отчетности полностью или частично отсутствовали; в-третьих, былиотмечены случаи дублирования финансовых данных о компаниях в 2015 и 2016 гг.
} 
и прогнозирования финансовой несостоятельности [16; 17; $1 ; 10$, с.157-158 и др.]. Методический инструментарий в этой области характеризуется большим разнообразием. Однако в качестве базовых показателей, как правило, используется довольно узкий набор финансовых показателей. Так, несмотря на неоспоримо высокую значимость денежных потоков в корпоративной финансовой диагностике, инвестиционном анализе и ценностноориентированном менеджменте $[2 ; 8 ; 6$, с. 41, 107], предпочтенияаналитиков в оценке обеспеченности долга компаний тяготеют к показателям бухгалтерского балансаи отчета о финансовых результатах. Таким образом, аналитическое значение денежных потоков несколько недооценивается, что и определило общее направление исследования.

Отметим еще два важных ракурса рассматриваемой проблематики. Первый из них касается соотношения ретроспективных и прогнозных методов оценки обеспеченности долга. Практика показывает, что макрофинансовые исследования в этой области в основном осуществляются методами ретроспективного анализа. Такой вывод следует, как минимум, из обзора методологии мониторинга финансовых систем[19, p. 681]. Высокую роль ретроспективный анализ обеспеченности долга имеет и в хозяйственной жизни организаций, отражая теоретические и методические рекомендации по финансовой диагностике, традиционному финансовому анализу, оценке финансовых рисков и пр. Значимые исключения в этом отношении представлены в сфереинвестиционной оценки, что касаетсяеще одного ракурса нашего исследования. Инструментарий инвестиционнойоценки самым непосредственным образом связан с прогнозныманализом [3; 6, с. 62]. Если речь идет об оценке инвестиционных проектов, обосновании решений по управлению инвестиционными активами, включая как финансовые активы, так и бизнес-единицы, прогнозная оценка незаменима, и во многих случаях приоритет принадлежит именно прогнозируемым денежным потокам, а не ретроспективным показателям баланса или отчета о финансовых результатах.

Обобщая обозначенные проблемные области, отметим, что перспективным направлением дальнейших исследований, связанных с оценкой обеспеченности долгакомпаний, является инвестиционный мониторинг.

- Во-первых, задачи инвестиционного мониторинга касаются и макро-, и микроэкономического уровней. К настоящему времени эти задачи не получили должного комплексного теоретического осмысления. Например, как и в оценке финансовой стабильности, в этой сфере не задействованы многие конструктивные решения, применяемые аналитиками на микроуровне.

- $\quad$ Во-вторых, инвестиционный мониторинг, призванный сопровождать управление инвестициями, не может игнорировать инструменты прогнозного анализа. Именно в этом направлении, по мнению авторов, имеет смысл развивать методические подходы к оценке обеспеченности долга, основанные на денежных потоках.

Таким образом, цель нашего исследования заключалась в разработке авторской модели прогнозной обеспеченности долга и обосновании ее аналитической значимости в инвестиционном мониторинге компаний.

В разделе «Методология исследования» представлены теоретические основы и ключевые этапы оценки прогнозной обеспеченности долга. Раздел «Результаты оценки прогнозной обеспеченности долга на примере транспортной компании» раскроет особенности применения предложенной методики, что позволит выявить ее преимущества и ограничения. В разделе «Выводы и рекомендации» обобщены особенности применения предложенной моделив практике инвестиционного мониторинга компаний.

\section{Методология исследования}

Оценку прогнозной обеспеченности долга, которая может быть выполнена за срок анализируемого инвестиционного проекта или за бессрочный период, предлагается осуществлять по соотношению совокупной инвестиционной стоимости и чистого долга компании:

$$
D C_{n}=I V_{t} / N D_{t}
$$

где: $D C$ - коэффициент обеспеченности долга; $I V_{t}-$ инвестиционная стоимостьна момент оценки $t ; N D_{t}-$ чистый долг на момент оценки $t ; n-$ прогнозный период (бессрочный или срок анализируемого проекта).

Раскроем финансовый смысл показателя. Следуя принципам оценки корпоративных обязательств БлэкаШоулза-Мертона (BSM-модель), чистый долг можно рассматривать как цену, которую собственники условно уплачивают кредиторам за возможность дальнейшего продолжения бизнеса. Надо заметить, что в оригинальной BSM-модели речь идет не о чистом долге, а о совокупной задолженности [20, p. 450; 453],однако оценка на основе чистого долга представляется нам более корректной, так как теоретически в любой момент времени часть задолженности может быть погашена за счет имеющихся денежных средств.

В том случае, когда стоимость компании как действующей (совокупная инвестиционная стоимость) превышает соответствующую цену (IV>ND), собственникам целесообразно удовлетворить требования кредиторов, что позволяет оценить обеспеченность долга положительно, и, следовательно, при общих равных 
принять соответствующее инвестиционное решение (к примеру, собственниками - о продолжении бизнеса, потенциальными инвесторами - о покупке финансовых активов компании). В то же время значение коэффициента обеспеченности долгаза срок анализируемого инвестиционного проекта также должно составлять больше единицы, иначе данный проект должен расцениваться как экономически нецелесообразный (подробнее об интерпретации возможных значений будет сказано в разделе «Выводы и рекомендации»).

Для оценки коэффициента обеспеченности долга на основе денежных потоков следует обосновать релевантный методический подход к оценке инвестиционной стоимости. Она может быть определена в рамках доходного подхода, с применением традиционной модели дисконтированных денежных потоков (DCF-модель). Однако, следует задаться вопросом, о каких видах свободного денежного потока и капитала идет речь?

В оценке обеспеченности долга можноиспользовать показатель денежного потока, значение которого представлено в финансовой отчетности предприятий как сальдо денежных потоков от текущих, инвестиционных и финансовых операций [см., например: 6 , с. 227, 228]. Но такой вариант не вполне отвечает логике модели, которой, на наш взгляд, в большей степени соответствует показатель свободного денежного потока (Free Cash Flow, FCF), позволяющий оценить возможность компании по обслуживанию капитала. Примечательно, что сопоставимые подходы к оценке обеспеченности долга применяются в анализе эффективности проектного финансирования [см., например: 11, с. 101-103].

Как известно, в зависимости от того, что требуется получить - стоимость собственного или совокупного инвестированного капитала, различаютдва вида денежных потоков:

- $\quad$ денежный поток на собственный капитал (FreeCashFlowtoEquity, FCFE);

- $\quad$ денежный поток на инвестированный капитал или «на фирму» (Free Cash Flowto Firm, FCFF).

Дисконтируя тот или иной вид денежного потока, мы оцениваем либо стоимость собственного капитала компании, либо стоимость всего инвестированного капитала, которая должна быть скорректирована на величину задолженности. Поскольку предложенный показатель оценки обеспеченности долга по своему финансовому смыслу корреспондирует с оценкой совокупной инвестиционной стоимости, нам следует использовать свободный денежный поток на инвестированный капитал. Однако в формулу его расчета предлагается ввести некоторые корректировки (рис. 1).

\begin{tabular}{|c|}
\hline Операционная прибыль (ОР) \\
\hline 5 \\
\hline + Прочие доходы (I $\left.\mathrm{I}_{\text {non-operating }}\right)$ \\
\hline S \\
\hline - Прочие расходы (без учета финансовых) $\left(\mathrm{C}_{\text {non-operating }}\right)$ \\
\hline$\sqrt{2}$ \\
\hline - Совокупный налог на прибыль (ТT) \\
\hline R \\
\hline Скорректированная чистая операционная прибыль (NOPAT $\left.{ }_{\text {adj }}\right)$ \\
\hline 尺 \\
\hline + Амортизация (A\&D) \\
\hline$S \zeta$ \\
\hline + (-) Снижение (рост) собственных оборотных средств (без учета денег) $(\Delta \mathrm{WC})$ \\
\hline 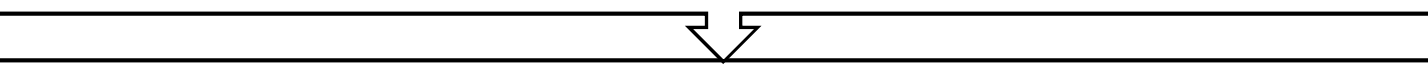 \\
\hline - Капитальные вложения (САРЕХ) \\
\hline 2 \\
\hline Скорректированный свободный денежный поток на инвестированный капитал $\left(\mathrm{FCFF}_{\text {adj }}\right)$ \\
\hline
\end{tabular}




\section{на инвестированный капитал $\left(F C F F_{a d j}\right)^{2}$}

Применяя предложенный подход, мы можем корректно оценить денежный поток, доступный инвесторам, что особенно важно в случае с российскими компаниями, которые зачастую характеризуются устойчиво высоким уровнем неоперационных (прочих) доходов. Далее обратимся к результатам апробации модели прогнозной обеспеченности долга на примере российской компании. В частности, продемонстрируем, как разница в оценке свободного денежного потока влияет на прогнозное значение обеспеченности долга.

\section{Результаты оценки прогнозной обеспеченности долга на примере транспортной компании}

Авторская модель оценки обеспеченности долга была апробирована на примере транспортной компании, оперирующей в одном из крупных портов Балтийского моря. Рассматриваемая компания предоставляет услуги по подаче-уборке вагонов на территории порта, услуги по аренде локомотива с экипажем, транспортноэкспедиторские услугами и так далее. Выбор компании обусловлен возрастающей ролью крупных портов Северо-Запада России в условиях выполнения поручения Президента РФ, который распорядился экспортировать российские грузы только через родные порты. Только в Петербурге и Ленобласти владельцы российских портовых терминалов до 2025 г. инвестируют в развитие мощностей более 1 трлн руб. ${ }^{3}$ Тот факт, что рассматриваемая отрасль в ближайшие годы будет динамично развиваться, делает ее, без сомнения, интересным объектом для исследования. Чтобы продемонстрировать различия в альтернативных оценках инвестиционной стоимости и обеспеченности долга, была выбрана компания со значительной долей неоперационных (по РСБУ «прочих») доходов. Все расчеты были основаны на ретроспективном анализе финансовой отчетности и последующем прогнозе. Для определения ставки дисконтирования использовалась модель оценки средневзвешенной стоимости капитала (WACC) (табл. 1, 2).

Таблица 1

\section{Оценка прогнозной обеспеченности долга с применением свободного денежного потока в традиционной интерпретации}

\begin{tabular}{|c|c|c|c|c|c|c|c|c|}
\hline Название показателя & $\begin{array}{l}\text { На дату } \\
\text { оценки }\end{array}$ & ПП-1* & ПП 2 & ПП 3 & ПП 4 & ПП 5 & ПП 6 & $\begin{array}{l}\text { Пост- } \\
\text { прогнозный } \\
\text { период }\end{array}$ \\
\hline Выручка, тыс. руб. & - & 298867 & 577060 & 603673 & 628125 & 653677 & 680379 & \\
\hline $\begin{array}{l}\text { Себестоимость, управ- } \\
\text { ленческие и коммерческие } \\
\text { расходы, тыс. руб. }\end{array}$ & - & -251842 & -486263 & -508688 & -529293 & -550824 & -573325 & \\
\hline Операц-ая прибыль, тыс. руб. & - & 47025 & 90798 & 94985 & 98833 & 102853 & 107055 & \\
\hline Налог на прибыль, тыс. руб. & - & -14836 & -28645 & -29966 & -31180 & -32448 & -33774 & \\
\hline $\begin{array}{l}\text { Чистая операционная } \\
\text { прибыль, тыс. руб. }\end{array}$ & - & 32190 & 62153 & 65019 & 67653 & 70405 & 73281 & \\
\hline Амортизация, тыс. руб. & - & 6669 & 13338 & 13338 & 13338 & 13338 & 13338 & \\
\hline Капиталовложения, тыс. руб. & - & -6669 & -14338 & -15077 & -15755 & -16464 & -17205 & \\
\hline $\begin{array}{l}\text { Увеличение собственного } \\
\text { оборотного капитала, тыс. } \\
\text { руб. }\end{array}$ & - & 0 & -1154 & -852 & -782 & -818 & -854 & \\
\hline $\begin{array}{l}\text { Свободный денежный поток } \\
\text { на инв-ный капитал }\left(\mathrm{FCFF}_{\mathrm{i}}\right) \text {, } \\
\text { тыс. руб. }\end{array}$ & - & 45528 & 90983 & 94285 & 97528 & 101025 & 104678 & 109389 \\
\hline Чистый долг $\left(\mathrm{ND}_{\mathrm{i}}\right)$ & - & 186181 & 113156 & 31157 & -59082 & -156587 & -260289 & \\
\hline $\mathrm{FCFF}_{\mathrm{i}} / \mathrm{ND}_{\mathrm{i}}$ & - & 0,24 & 0,80 & 3,03 & $-1,65$ & $-0,65$ & $-0,40$ & \\
\hline Ставка дисконтирования, \% & & & & & 18,3 & & & \\
\hline $\begin{array}{l}\text { Текущая стоимость денежных } \\
\text { потоков, тыс. руб. }\end{array}$ & - & 43655 & 76908 & 67371 & 58908 & 51581 & 45179 & \\
\hline $\begin{array}{l}\text { Стоимость реверсии, тыс. } \\
\text { руб. }\end{array}$ & - & & & & & & & 792672 \\
\hline $\begin{array}{l}\text { Текущая стоимость реверсии, } \\
\text { тыс. руб. }\end{array}$ & 342113 & & & & & & & \\
\hline
\end{tabular}

${ }^{2}$ Составлено авторами.

${ }^{3}$ СологубА., КовтунН. Здесьбудеттриллион. В порты Петербурга и Ленобласти за 8 лет привлекут более 1 трлн рублей// Деловой Петербург, 8 июня 2017 г.URL: https://www.dp.ru/a/2017/06/07/Portitrillioneri. 
Текущая стоим. инвестиро-

ванного капитала $\left(\mathrm{IV}_{0}\right)$, тыс.

руб.

Коэффициент обеспечен-

ности долга (DC $\left.=\mathrm{IV}_{0} / \mathrm{ND}_{0}\right)$
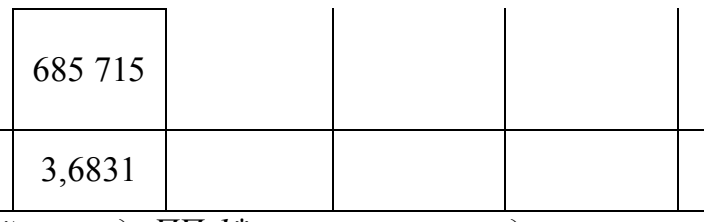

Примечание: ПП - прогнозный период; ПП-1* - второе полугодие первого периода; ПП-2 - ПП-6 - 2 - 6 годы прогнозного периода соответственно (составлено авторами)

Таблица 2

\section{Оценка прогнозной обеспеченности долга с применением скорректированного значения свободного денежного потока}

\begin{tabular}{|c|c|c|c|c|c|c|c|c|}
\hline Название показателя & $\begin{array}{l}\text { На дату } \\
\text { оценки }\end{array}$ & ПП-1* & ПП 2 & ПП 3 & ПП 4 & ПП 5 & ПП 6 & $\begin{array}{c}\text { Пост- } \\
\text { прогнозный } \\
\text { период }\end{array}$ \\
\hline Выручка, тыс. руб. & - & 298867 & 577060 & 603673 & 628125 & 653677 & 680379 & - \\
\hline $\begin{array}{l}\text { Себестоимость, } \\
\text { управленческие и } \\
\text { коммерческие расходы, тыс. } \\
\text { руб. }\end{array}$ & - & -251842 & -486263 & -508688 & -529293 & -550824 & -573325 & - \\
\hline $\begin{array}{l}\text { Операционная прибыль, } \\
\text { тыс. руб. }\end{array}$ & - & 47025 & 90798 & 94985 & 98833 & 102853 & 107055 & - \\
\hline $\begin{array}{l}\text { Прочие доходы и расходы, } \\
\text { тыс. руб. }\end{array}$ & - & 29707 & 57359 & 60004 & 62435 & 64975 & 67629 & - \\
\hline $\begin{array}{l}\text { Прибыль до уплаты } \\
\text { процентов и налогов, тыс. } \\
\text { руб. }\end{array}$ & - & 76732 & 148157 & 154990 & 161268 & 167828 & 174684 & - \\
\hline Налог на прибыль, тыс. руб. & - & -15346 & -29631 & -30998 & -32254 & -33566 & -34937 & - \\
\hline $\begin{array}{l}\text { Чистая операционная } \\
\text { прибыль, тыс. руб. }\end{array}$ & - & 61386 & 118526 & 123992 & 129014 & 134262 & 139747 & - \\
\hline Амортизация, тыс. руб. & - & 6669 & 13338 & 13338 & 13338 & 13338 & 13338 & - \\
\hline $\begin{array}{l}\text { Капиталовложения, тыс. } \\
\text { руб. }\end{array}$ & - & -6669 & -14338 & -15077 & -15755 & -16464 & -17205 & - \\
\hline $\begin{array}{l}\text { Увеличение собственного } \\
\text { оборотного капитала, тыс. } \\
\text { руб. }\end{array}$ & - & 0 & -1154 & -852 & -782 & -818 & -854 & - \\
\hline $\begin{array}{l}\text { Свободный денежный поток } \\
\text { на инвестированный } \\
\text { капитал }\left(\mathrm{FCFF}_{\mathrm{i}}\right) \text {, тыс. руб. }\end{array}$ & - & 74724 & 147355 & 153258 & 158889 & 164882 & 171144 & 178845 \\
\hline Чистый долг $\left(\mathrm{ND}_{\mathrm{i}}\right)$ & - & 156985 & 27588 & -113384 & -264984 & -426346 & -596514 & \\
\hline $\mathrm{FCFF}_{\mathrm{i}} / \mathrm{ND}_{\mathrm{i}}$ & - & 0,48 & 5,34 & $-1,35$ & $-0,60$ & $-0,39$ & $-0,29$ & - \\
\hline Ставка дисконтирования, \% & \multicolumn{8}{|c|}{18,3} \\
\hline $\begin{array}{l}\text { Текущая стоимость } \\
\text { денежных потоков, тыс. руб. }\end{array}$ & - & 71649 & 124561 & 109510 & 95971 & 84185 & 73865 & - \\
\hline $\begin{array}{l}\text { Стоимость реверсии, тыс. } \\
\text { руб. }\end{array}$ & - & - & - & - & - & - & - & 1295981 \\
\hline $\begin{array}{l}\text { Текущая стоимость } \\
\text { реверсии, тыс. руб. }\end{array}$ & 559339 & - & - & - & - & - & - & - \\
\hline $\begin{array}{l}\text { Текущая стоимость } \\
\text { инвестированного капитала } \\
\left(\mathrm{IV}_{0}\right) \text {, тыс. руб. }\end{array}$ & $\begin{array}{c}1119 \\
080\end{array}$ & - & - & - & - & - & - & - \\
\hline $\begin{array}{l}\text { Коэффициент } \\
\text { обеспеченности долга ( } \\
\left.\mathrm{DC}=\mathrm{IV}_{0} / \mathrm{ND}_{0}\right)\end{array}$ & 7,1286 & & & & & & & \\
\hline
\end{tabular}

Примечание: ПП - прогнозный период; ПП- ${ }^{*}$ - второе полугодие первого периода; ПП-2 - ПП-6-2 - 6 годы прогнозного периода соответственно (составлено авторами)

Таблицы показывают значительную разницу в результатах, которые были получены альтернативными способами. Так, текущая стоимость инвестированного капитала при скорректированном значении денежного 
потока более чем на $60 \%$ превышает значение, полученное при традиционном расчете. Обеспеченность долга также существенно возрастает, так как в расчет принимаются значительные прочие доходы.

Это демонстрирует, как важно правильно оценивать денежный поток, доступный для обслуживания инвестированного капитала. Однако в обоих случаях прогнозная обеспеченность долга существенно превышает единицу, что положительно характеризует финансовую устойчивость компании как потенциального объекта инвестиций.

Рассмотрим результаты, полученные рекомендуемым способом. В отдельных периодах чистый долг принимает отрицательные значения, не позволяя корректно получить прогнозную оценку. Это вызвано тем, что величина чистого долга становится отрицательной по причине превышения величины денежных средств над величиной задолженности, то есть на данном этапе можно предположить отсутствие у компании необходимости привлечения дополнительных источников финансирования по причине наличия собственных источников.

Отметим также, что значительная величина денежных средств свидетельствует о наличии ограничений в части доступных форм инвестирования, что в целом характерно для относительно небольших российских компаний. Однако есть основания полагать, что в условиях бурного развития отрасли, у анализируемойкомпании будет возможность скорректировать свои инвестиционно-финансовые планы.

\section{Выводы и рекомендации}

Предложенная модель оценки прогнозной обеспеченности долга апеллирует к принципам формирования теоретических моделей финансовой несостоятельностифирмы $[10$, с. 161], в чем есть определенные аналитические преимущества. В отличие от эмпирических, такие модели более устойчивы к изменениям условий аналитических задач, не требуя систематической проверки в контексте специфики компании. Что же касается эмпирических моделей, зачастую важна не только индивидуальная и отраслевая, но и страновая специфика [7, с. 57]. К примеру, Россия относится к группе формирующихся финансовых рынков [21], для которых в целом характерны более низкие уровни зависимости компаний от долгового финансирования, чем для развитых $[13$, c. 12].

Что касается возможности применения модели прогнозной обеспеченности долга для оценки и прогноза финансовой стабильности конкретной компании, то успешность ее применения во многом будет зависеть от понимания еe инвестиционно-финансовых планов. Таким образом, оценка финансовой стабильности с применением данного показателя будет релевантной ровно на столько, на сколько будут детализированы планы компании относительно инвестиций и источников финансирования ее деятельности. Не менее важен и общий уровень развития финансового рынка, влияющий на реализацию инвестиционно-финансовых планов компании.

В целом рекомендации по применению модели обеспеченности долгав целях инвестиционного мониторингакомпанийможно обобщить следующим образом (табл. 3).

Таблица 3

Рекомендации по инвестиционному мониторингу с применением модели оценки обеспеченности долга

\begin{tabular}{|l|l|l|}
\hline \multicolumn{1}{|c|}{ Вопрос мониторинга } & \multicolumn{1}{|c|}{ Период оценки DC } \\
\cline { 2 - 3 } & \multicolumn{1}{|c|}{ Срок проекта } & \multicolumn{1}{|c|}{ Бессрочный период } \\
\hline $\begin{array}{l}\text { Оценка инвестиционной } \\
\text { привлекательности компании при } \\
\text { DC } 1 *\end{array}$ & $\begin{array}{l}\text { Положительная: проект } \\
\text { по анализируемому } \\
\text { критерию } \\
\text { экономически } \\
\text { целесообразен }\end{array}$ & $\begin{array}{l}\text { Положительная: компания способна обслуживать } \\
\text { инвестированный капитал, признак финансовой } \\
\text { несостоятельности не выявлен }\end{array}$ \\
\hline $\begin{array}{l}\text { Оценка инвестиционной } \\
\text { привлекательности компании при } \\
\text { DC< } 1\end{array}$ & $\begin{array}{l}\text { Отрицательная: проект } \\
\text { по анализируемому } \\
\text { критерию } \\
\text { экономически } \\
\text { нецелесообразен }\end{array}$ & $\begin{array}{l}\text { Отрицательная: компания по анализируемому } \\
\text { критерию финансово несостоятельна }\end{array}$ \\
\hline $\begin{array}{l}\text { Оценка инвестиционной } \\
\text { привлекательности компании при } \\
\text { положительной динамике DC** }\end{array}$ & \multicolumn{1}{|c|}{-} & $\begin{array}{l}\text { Положительная: расширяются возможности } \\
\text { компании по обслуживанию инвестированного } \\
\text { капитала }\end{array}$ \\
\hline $\begin{array}{l}\text { Оценка инвестиционной } \\
\text { привлекательности компании при } \\
\text { отрицательной динамике DC }\end{array}$ & $\begin{array}{l}\text { Отрицательная: сокращаются возможности } \\
\text { компании по обслуживанию инвестированного } \\
\text { капитала }\end{array}$ \\
\hline
\end{tabular}


Примечание: DC-коэффициент обеспеченности долга; ${ }^{*}$ пи $D C \approx 1$ выводы о финансовом состоянии компании требуют экспертной оценки; ** резкое повыщение показателя требует углубленной оченки (составлено авторами)

Как видно из таблицы, данные рекомендации ориентированы в первую очередь на задачи микрофинансового анализа и, следовательно, будут в первую очередь востребованы инвесторами и менеджерами анализируемых компаний. Однако, по мнению авторов, значимость предложенной модели прогнозной обеспеченности долга не ограничивается вопросами инвестиционного мониторинга, внося определенный вклад в развитие таких направлений финансовой науки и практики, как управление структурой капитала, финансовая реструктуризация, оценка финансовых рисков, корпоративная финансовая диагностика и мониторинг финансовой стабильности, что определяет возможные траектории дальнейших исследований.

\section{Литература}

1. Абрамишвили Н. Р. Динамическая модель оценки платежеспособности должника: к вопросу разработки стандартов финансового анализа для арбитражных управляющих // Финансовая аналитика: проблемы и решения. 2015. № 38. С. 30-41.

2. Валдайщев C. B. Денежные потоки в оценке и управлении стоимостью компании // Вестник СанктПетербургского университета. Серия 5: Экономика. 2009. № 3. С. 105-123.

3. Дамодаран А. Инвестиционная оценка: Инструменты и методы оценки любых активов / А. Дамодаран: пер. с англ. - 9-е изд., перераб. и доп. - М.: Альпина Паблишер, 2016. 1316 с.

4. Донеи C., Пономаренко A. Индикаторы долговой нагрузки // Серия докладов об экономических исследованиях. Банк России. 2015. № 5.24 с.

5. Донеи C., Могилат A. Кредитование и финансовая устойчивость российских промышленных компаний: микроэкономические аспекты анализа // Серия докладов об экономических исследованиях. Банк России. 2016. № 16. 25 c.

6. Иванов В.В. Корпоративное финансовое планирование / В. В. Иванов, Н. Н. Цытович. - СПб.: БАН, Нестористория, 2009. - $332 \mathrm{c.}$

7. Кораблева И. Измерение риска дефолта частных российских фирм с помощью модели Moody’s Analytics Risk Calc // Риск-менеджмент. 2011. № 3. С. 54-65.

8. Лукасевич И. Я. Анализ денежных потоков как инструмент принятия решений в бизнесе // Финансы. 2016. № 7. С. 47-51.

9. Львова Н.А. Финансовая диагностика российских предприятий с применением модели Альтмана для развитых и формирующихся рынков // Финансовая аналитика: проблемы и решения. 2015. №7. С. 37 - 45.

10. Львова Н.А.Финансовая концепция банкротства предприятий: содержание и потенциал развития // Менеджмент и бизнес-администрирование. 2017. №1. С. 155 - 163.

11. Никонова И.А. Проектный анализ и проектное финансирование. - М.: Альпина-Паблишер, 2012. 154 с.

12. Обзор финансовой стабильности. - II - III кв. 2016 г. - М.: Банк России, 2016. 65 с.

13. Пономаренко, А., Рожкова А., Селезнев С. Макроэкономические взаимосвязи: роль зависимости от долгового финансирования // Серия докладов об экономических исследованиях. Банк России. 2017. № 24. 30 с.

14. Моисеев С. Р., Лобанова М. А. Концепция макропруденциальной политики // Деньги и кредит. 2013. № 7. C. $46-54$.

15. Мински $X$. Стабилизируя нестабильную экономику. - М.; СПб: Изд-во Инст-та Гайдара, Факультет свободных искусств и наук СПбГУ, 2017. 624 с.

16. Солодухина, А.В., Репин Д.В. В поисках решения загадки структуры капитала: поведенческий подход // Корпоративные финансы. 2008. № 1. С. 103-118.

17. Теплова T.B. Работа на заемном капитале. Оптимум долговой нагрузки компании: от теоретических концепций к практическим модельным обоснованиям (Часть 1) // Управление корпоративными финансами. 2013. № 4. C. 198-208.

18. Abramishvili N.R. Free cash flow potential in assessing financial stability of nonfinancial businesses (the case of Russia) / N.R. Abramishvili, N.A. Lvova, N.S. Voronova, A.V. Kazansky // The proceedings of the $30^{\text {th }}$ IBIMA conference "Vision 2020: Sustainable Economic Development, Innovation Management, and Global Growth". IBIMA, 2017. P. 1376-1385.

19. Lvova $N$. Developing methodology of monitoring companies' financial stability: abnormal profitability evaluation / N. Lvova, N. Pokrovskaia, N. Abramishvili, V. Ivanov // Proceedings of the 28th International Business Information Management Association Conference - Vision 2020: Innovation Management, Development Sustainability, and Competitive Economic Growth. - IBIMA, 2016. P. 681-688.

20. Merton R. On the pricing of corporate debt: the risk structure of interest rates // Journal of Finance. 1974. Vol. 29. P. 449-470. 
21. Teso Y. These are 2018's most (and least) attractive emerging markets / Y. Teso, M. Kondo, H. Dormido // Bloomberg Markets. - January 22, 2018. - URL: https://www.bloomberg.com/news/articles/2018-01-21/emergingmarket-scorecard-supports-mexico-and-turkey-over-india?cmpid=socialflow-facebookbusiness\&utm_content=business\&utm_campaign=socialflow-organic\&utm_source=facebook\&utm_medium=social.

\section{References}

1. Abramishvili N. R. Dinamicheskaya model' ocenki platezhesposobnosti dolzhnika: k voprosu razrabotki standartov finansovogo analiza dlya arbitrazhnyh upravlyayushchih // Finansovaya analitika: problemy i resheniya. 2015. № 38. P. 30-41.

2. Valdajcev S. V. Denezhnye potoki v ocenke i upravlenii stoimost'yu kompanii // Vestnik Sankt-Peterburgskogo universiteta. Seriya 5: EHkonomika. 2009. № 3. P. 105-123.

3. Damodaran A. Investicionnaya ocenka: Instrumenty i metody ocenki lyubyh aktivov / A. Damodaran: per. s angl. 9-e izd., pererab. i dop. - M.: Al'pina Pablisher, 2016. 1316 p.

4. Donec S., Ponomarenko A. Indikatory dolgovoj nagruzki // Seriya dokladov ob ehkonomicheskih issledovaniyah. Bank Rossii. 2015. № 5.24 p.

5. Donec S., Mogilat A. Kreditovanie i finansovaya ustojchivost' rossijskih promyshlennyh kompanij: mikroehkonomicheskie aspekty analiza // Seriya dokladov ob ehkonomicheskih issledovaniyah. Bank Rossii. 2016. № $16.25 \mathrm{p}$.

6. Ivanov V.V. Korporativnoe finansovoe planirovanie / V. V. Ivanov, N. N. Cytovich. - SPb.: BAN, Nestor-istoriya, 2009. - $332 \mathrm{p}$.

7. Korableva I. Izmerenie riska defolta chastnyh rossijskih firm s pomoshch'yu modeli Moody’s Analytics Risk Calc // Risk-menedzhment. 2011. № 3. P. 54-65.

8. Lukasevich I. YA. Analiz denezhnyh potokov kak instrument prinyatiya reshenij v biznese // Finansy. 2016. № 7. P. 47-51.

9. L'vova N.A. Finansovaya diagnostika rossijskih predpriyatij s primeneniem modeli Al'tmana dlya razvityh i formiruyushchihsya rynkov // Finansovaya analitika: problemy i resheniya. 2015. №7. P. 37 - 45.

10. L'vova N.A.Finansovaya koncepciya bankrotstva predpriyatij: soderzhanie i potencial razvitiya // Menedzhment $i$ biznes-administrirovanie. 2017. №1. P. 155 - 163.

11. Nikonova I.A. Proektnyj analiz i proektnoe finansirovanie. - M.: Al'pina-Pablisher, 2012. 154 p.

12. Obzor finansovoj stabil'nosti. - II - III kv. 2016 g. - M.: Bank Rossii, 2016. 65 p.

13. Ponomarenko, A., Rozhkova A., Seleznev S. Makroehkonomicheskie vzaimosvyazi: rol' zavisimosti ot dolgovogo finansirovaniya // Seriya dokladov ob ehkonomicheskih issledovaniyah. Bank Rossii. 2017. № 24. 30 p.

14. Moiseev S. R., Lobanova M. A. Koncepciya makroprudencial'noj politiki // Den'gi i kredit. 2013. № 7. P. 46-54.

15. Minski H. Stabiliziruya nestabil'nuyu ehkonomiku. - M.; SPb: Izd-vo Inst-ta Gajdara, Fakul'tet svobodnyh iskusstv i nauk SPbGU, 2017. 624 p.

16. Soloduhina, A.V., Repin D.V. V poiskah resheniya zagadki struktury kapitala: povedencheskij podhod // Korporativnye finansy. 2008. № 1. P. 103-118.

17. Teplova T.V. Rabota na zaemnom kapitale. Optimum dolgovoj nagruzki kompanii: ot teoreticheskih koncepcij $\mathrm{k}$ prakticheskim model'nym obosnovaniyam (CHast' 1) // Upravlenie korporativnymi finansami. 2013. № 4. S. 198-208.

18. Abramishvili N.R. Free cash flow potential in assessing financial stability of nonfinancial businesses (the case of Russia) / N.R. Abramishvili, N.A. Lvova, N.S. Voronova, A.V. Kazansky // The proceedings of the 30th IBIMA conference "Vision 2020: Sustainable Economic Development, Innovation Management, and Global Growth". IBIMA, 2017. P. 1376-1385.

19. Lvova N. Developing methodology of monitoring companies' financial stability: abnormal profitability evaluation / N. Lvova, N. Pokrovskaia, N. Abramishvili, V. Ivanov // Proceedings of the 28th International Business Information Management Association Conference - Vision 2020: Innovation Management, Development Sustainability, and Competitive Economic Growth. - IBIMA, 2016. P. 681-688.

20. Merton R. On the pricing of corporate debt: the risk structure of interest rates // Journal of Finance. 1974. Vol. 29. P. 449-470.

21. Teso Y. These are 2018's most (and least) attractive emerging markets / Y. Teso, M. Kondo, H. Dormido // Bloomberg Markets. - January 22, 2018. - URL: https://www.bloomberg.com/news/articles/2018-01-21/emergingmarket-scorecard-supports-mexico-and-turkey-over-india?cmpid=socialflow-facebookbusiness\&utm_content=business\&utm_campaign=socialflow-organic\&utm_source=facebook\&utm_medium=social. 